\title{
A liderança no processo de ensino-aprendizagem como uma estratégia de fortalecimento da dodiscência
}

\author{
Leadership in the teaching-learning process as a strategy to strengthen dodiscence
}

\author{
Willyane Freire da Silva ${ }^{1}$ (D) , Daniel Costa Assunção ${ }^{2}$ (iD \\ ${ }^{1}$ Instituto Federal de Pernambuco (IFPE), Brasil, Mestre em Gestão do Desenvolvimento Local Sustentável (UFPE), e-mail: \\ freirewillyane@gmail.com \\ ${ }^{2}$ Instituto Federal de Pernambuco (IFPE), Brasil, Mestre em Gestão Empresarial (FBV), e-mail: danielc.assuncao@gmail.com
}

\section{RESUMO}

Os avanços das Tecnologias da Informação e Comunicação e o acesso às informações fez com paradigmas de que o docente é o detentor de saber e um agente inacessível fossem repensados. Cada vez mais, o processo educativo tem no discente e em sua participação uma peça imprescindível à construção dos saberes e o docente que o guia estrategicamente na perspectiva de ensino qualificado. Nesse sentido, Paulo Freire trouxe a abordagem da expressão dodiscência como aquela prática capaz de concatenar a atuação do docente e do discente conjuntamente, ao relevar que tais premissas, no processo de ensino a ambos ensinam e aprendem mediante experiências, vivências, interações e partilha. Todavia, percebe-se que para que esse processo educativo se dê corretamente, é necessária uma relação de confiança, interesse, respeito e estímulo daqueles que guiam os estudantes. Além disso, faz-se necessário um espírito de liderança no docente para ora inspirar e ora estabelecer uma construção de conhecimento fortalecida e eficaz. Assim, analisou-se a aproximação epistemológica entre os conceitos da dodiscência e da liderança, de modo que, quando integrados fortalecem o processo de ensino aprendizagem. Tratouse de uma pesquisa dedutiva e se abordaram temas e conceitos-chave de autores como Freire (2010), Gomez; Sacristán (2007), Ibernón (2008), Gadotti (2009), Robbins; Judge; Sobral (2010), entre outros. Buscou-se lançar luzes sobre a relevância do desenvolvimento da dodiscência no processo educativo e ampliar a discussão da necessária liderança a ser adotada pelo docente na condução de tal prática.

Palavras-chave: Liderança. Ensino. Aprendizagem.

\begin{abstract}
The advances in information and communication technologies and access to information have led to paradigms that the teacher is the holder of knowledge and an inaccessible agent should be rethought. Increasingly, the educational process has in the student and in his participation an essential piece for the construction of knowledge and the teacher as the one who guides him in the best way to achieve this construction. In this sense, Paulo Freire brought the approach of the expression dodiscence as that practice capable of concatenating the performance of the teacher and the student together, by revealing that such premises, in the teaching-learning process, both teach and learn through experiences, experiences, interactions and sharing. However, it is clear that for this educational process to take place correctly, a relationship of trust, interest, respect and encouragement from those who guide the students is necessary, a spirit of leadership in the teacher is necessary in order to inspire and sometimes establish a strengthened and effective knowledge building. Thus, the epistemological approximation between the concepts of dodiscence and leadership was analyzed, so that, when integrated, they strengthen the teaching-learning process. It was a deductive research and key themes and concepts from authors such as Freire (2010), Gomez; Sacristán (2007), Ibernón (2008), Gadotti (2009), Robbins; Judge; Sobral (2010), among others. We sought to shed light on the relevance of the development of dodiscence in the educational process and to expand the discussion of the necessary leadership to be adopted by the teacher in conducting such practice.
\end{abstract}

Keywords: Leadership. Teaching. Learning. 


\section{INTRODUÇÃO}

Na sociedade contemporânea, cada vez mais, consolida-se o paradigma de que a educação é o melhor caminho para o desenvolvimento da sociedade, pois prepara o indivíduo para o convívio social, oportunizando-o à participação ativa do processo de transformação da mesma. Desse modo, possibilita o desenvolvimento da capacidade crítica da realidade em que está inserido, habilitando-o à produção de saberes (IBERNÓN, 2008).

Nessa perspectiva, subsidiar a relação de ensino-aprendizagem entre educador e educando para a construção de conhecimentos e, por sua vez, a formação de cidadãos críticos e conscientes do seu papel na sociedade é um desafio à educação do Século XXI. Esse desafio, nos contextos formativos, decorre de estarmos inseridos em uma sociedade informacional, cuja a possibilidade de acesso às informações foi facilitada e acelerada por meio dos avanços tecnológicos (COUTINHO; LISBOA, 2011).

Com isso, desenvolver um processo de ensino aprendizagem inserido num contexto em que a sociedade se caracteriza por ser constantemente pensada e transformada, tendo o educando como sujeito ativo na transformação das realidades em que estamos inseridos, é necessário adaptar o processo educativo à capacidade de estímulo à sua reflexão e à curiosidade para que ele possa ser capaz de apreender novos conhecimentos, questioná-los e, até mesmo, recriá-los (FREIRE, 2011).

Para isso, com o advento da informatização associado à necessidade de formar sujeitos críticos, autônomos e atuantes, percebeu-se a necessidade da evolução dos métodos de ensino e aprendizagem tendo o educando, suas experiências e conhecimentos a favor da formação de novos saberes (DEMO, 2011).

Dessa forma, é relevante construir estratégias no processo educativo, cujos estudantes se tornem parte integrante, envolvendo-os, buscando o desenvolvimento da capacidade de reflexão e estimulando nele o conhecimento de seu papel na sociedade como agente de transformação dos espaços em que atua. Para, com isso, impulsionar a formação de sujeitos com um olhar mais crítico, com disposição para reconhecer sua relevância em prol de uma sociedade mais justa, atuante e preocupada com o planeta (GADOTTI, 2009).

Todavia, o grande desafio é que, por um lado, têm-se docentes que possuem o conhecimento, mas, nem sempre, sabe envolver o estudante para se tornar ativo no processo educativo nem com habilidades comportamentais para guiá-lo à centralidade do ensino. Por 
outro lado, tem-se, ainda, estudantes que nem sempre querem ou se sentem inspirados para se tornarem atuantes e co-responsáveis pelo processo educativo, seja porque não reconhece a importância de ser partícipe do ato de ensinar e aprender seja porque não estabelece uma relação de confiança e abertura com o docente (LICHTENTHALER; FISCHBACH, 2018; GOMEZ; SACRISTÁN, 2007).

Nesse contexto, é imprescindível que o desenvolvimento das estratégias voltadas à construção do conhecimento na sala de aula seja como uma rede viva de troca, criação e transformação de significados para promover impactos na formação dos estudantes. Para isso, buscou-se compreender uma relação com a liderança a ser desenvolvida pelo docente como uma importante estratégia para o exercício da dodiscência, ou seja, a busca por um ensino em que ambos ensinam e ambos aprendem mediatizados pelo mundo, como ressalta (FREIRE, 2010; STOCKER, 2018; MANDELLI; LORIGGIO, 2018).

Este estudo se justifica pela necessidade da compreensão de como a liderança exercida pelo docente pode auxiliar no processo educativo pautado na dodiscência como propulsora de um ensino que visa à formação de sujeitos criativos, preocupados com problemas que o circundam, envolvidos com a prática e um ensino contextualizado visando à transformação social (PAUNOVA, 2017). Tendo como objetivo geral analisar a aproximação epistemológica entre os conceitos da dodiscência e da liderança na perspectiva do fortalecimento do ensino aprendizagem.

Justifica-se a necessidade desse estudo em decorrência da ausência de estudos que abordem a dodiscência com a liderança, tendo sido encontrados pesquisas que relacionam a liderança e a docência, a relevância do líder gestor, o docente líder, tendo em pauta a epistemologia e relação de fortalecimento no processo de ensino aprendizagem.

As dimensões abordadas foram dialogicidade, problematização, educação século XXI e relação de ensino-aprendizagem em se tratando da dodiscência. No que diz respeito à liderança, foram discutidas as dimensões comportamentais e de relação interpessoal, tais como mutualidade, envolvimento, envolvimento, confiança, persuasão, feedback e retroalimentação (IBERNÓN, 2008).

\section{REFERENCIAL TEÓRICO}

Revista Expectativa, Toledo/PR, v.20, n. 3, p. 71-87, jul./set., 2021. 


\subsection{DODISCÊNCIA}

A dodiscência é um termo utilizado por Paulo Freire para indicar a atuação mútua no processo de ensino e aprendizagem, em que ambos, discentes e docentes, aprendem e ensinam, como sujeitos de aprendizagem (FREIRE, 2010; SILVA, 2013).

Trata-se da junção das palavras docente e discente com intuito de expressar que o docente deve sempre estar disposto a aprender com o que faz e com o próprio discente, que, mediatizado pela sua vivência histórico-social, pela sua experiência e saberes, torna-se capaz de promover interações dialógicas. Para o autor, essa interação dialógica enriquece o verdadeiro sentido da aprendizagem e ambos crescem conjuntamente em prol de um bem comum (FREIRE, 2010; SILVA, 2013).

Essa interação dialógica entre eles busca desenvolver sujeitos reflexivos em suas ações, antes delas e depois delas, de modo que haja uma contínua auto-observação e busca pela autoformação, enquanto parte integrante da aprendizagem contínua (GADOTTI, 2009).

\subsection{DODISCÊNCIA: DIALOGICIDADE E PROBLEMATIZAÇÃO}

A dialogicidade na dodiscência não é a mera troca de informações de ideias, mas uma condução para investigação da realidade, de modo a emergir conteúdos, significados e produção de novos conhecimentos, partindo dos pressupostos que a apreensão do conhecimento é feita a partir do estabelecimento de dúvidas, conflitos, reflexões como parte integrante do processo educativo (FREIRE, 2011; IBERNÓN, 2008).

Assim, faz-se necessário que docentes e discentes se abram ao aprendizado e que assumam a necessidade de ser continuadamente curioso, aberta e propícia ao processo dialógico (FREIRE, 2011).

Outrossim, o processo educativo em que é construído por meio da dodiscência tem sua devida efetividade, pois, como revelam Melo e Urbanetz (2008), não se pode pensar cientificamente o tempo todo, uma vez que é importante que as escolas permitam ao estudante a construção de conhecimentos que o façam superar as situações corriqueiras, que são vivenciadas por cada indivíduo, sabendo-se que não há acaso, mas produto do processo educativo por meio da apropriação dos conhecimentos acumulados.

Revista Expectativa, Toledo/PR, v.20, n. 3, p. 71-87, jul./set., 2021. 
Concorda-se com Freire (2010, p.80) ao revelar que "o educador problematizador (re)faz, constantemente, seu ato cognoscente, na cognoscividade dos educandos". Com isso, no desenvolvimento da dodiscência, deverá o docente, ao conduzir o processo de ensino aprendizagem, preocupar-se com a problematização estimulando a curiosidade e a capacidade de reflexão para produção de novos conhecimentos.

Nesse contexto da dodisdência, problematizar o sujeito é torná-lo cidadão do mundo como seres no mundo e com o mundo e quanto mais são conduzidos à problematização, mais desafiados se sentirão e, por sua vez, buscarão corresponder tais desafios (GOMEZ; SACRISTÁN, 2007).

Tais desafios podem ser considerados como problemas, em que os mesmos poderão ser capazes de criar soluções aplicáveis às pesquisas, às situações diárias, às necessidades de um grupo, aos gargalos organizacionais. Afinal, a problematização auxilia na ampliação para outras dimensões, a partir da própria ação-reflexão-ação dos educandos, de modo a enriquecer o processo de ensino - aprendizagem (IBERNÓN, 2008; FREIRE, 2010).

Tem-se, com isso, a formação de um sujeito com um desenvolvimento cognitivo capaz de lidar com questões relacionadas à solidariedade, à cidadania, à coletividade, afinal, o para que o ser humano desenvolva a consciência coletiva da preocupação com o que está à sua volta é imprescindível uma formação para além dos muros institucionais (VIGOTSKY, 1991).

As autoras Diesel, Baldez e Martins (2017) abordam que as construções mentais necessárias à efetivação do educando no processo de ensino aprendizagem, pautado na dodiscência, são capazes de permitir que o aprendiz tenha uma efetividade maior em sala de aula, a partir da imaginação, organização de dados, criação de hipóteses, sugestões de decisões, soluções e observações.

Concorda-se com Halal (2009, p. 101), ao revelar que "somente por meio de ações e reflexões é que se adquire saberes necessários para aprender a conhecer, a ser, a fazer e a conviver", sendo o mesmo sujeito de sua própria aprendizagem de forma contínua.

Outrossim, "a educação terá um papel determinante na criação da sensibilidade social necessária para reorientar a humanidade" (ASSMANN, 2001, p. 26).

Esses significados, quando atrelados à compreensão do mundo em que se está inserido, reflete na busca pelo desenvolvimento da criticidade e estimula o exercício da curiosidade, que para Freire (2011, p.85) tal ato "convoca a imaginação, a intuição, as emoções, a capacidade de 
conjecturar, de comparar, na busca da perfilização do objeto ou do achado de sua razão de ser (...)", a partir de um processo de transitividade da nossa própria auto-observação e consciência.

Em complemento, Morán (2014) ressalta a relevância do desenvolvimento de projetos em sala de aula para o desenvolvimento da criticidade do estudante, pois levanta problemáticas e pode associar às reais vivências do estudante, de modo que, a partir da integração entre saberes corriqueiros e teorias estabelecidas, o discente seja capaz de apreender conhecimentos e aplicálos à sua vida acadêmica, profissional e pessoal.

Esses projetos em sala de aula também auxiliam o fortalecimento da dodiscência, pois evidenciam a construção de caminhos da problematização e da busca por soluções técnicas e inovadoras, promovendo o engajamento do aluno na busca por novas aprendizagens e novos caminhos. Dessa forma, tem-se o estímulo ao exercício da autonomia do sujeito e da capacidade de tomar decisões diante dos cenários que enfrentará no seu exercício profissional futuro (MORIN, 2011).

Com isso, a dodiscência reconhece o potencial do educando em estar na centralidade do processo de ensino e aprendizagem, a partir de sua realidade seja organizacional seja enquanto cidadão, porém sendo parte de uma sociedade em que atua, modifica, opina e transforma (SILVA, 2013; FREIRE, 2010).

No outro lado, em um papel, ainda mais desafiante, tem-se o docente que, muito mais que planejar sua aula, planejará como resgatará o melhor de cada estudante e o caminho para reconhecer a capacidade cognitiva deles (MORAN, 2014; MENDES, 2013). Nesse sentido, a dodiscência surge como aliada para colocar em prática o ensino necessário à formação de pessoas no Século XXI, cuja informação está, cada vez mais, democratizada e acessível.

\subsection{A DODICÊNCIA E A EDUCAÇÃO NO SÉCULO XXI}

$\mathrm{Na}$ sociedade informacional, o grande diferencial dos educandos não é o acesso à informação, uma vez que elas estão postas em diferentes formas e lugares, mas sim o desenvolvimento da capacidade para tratamento e processamento dessas informações, até mesmo, para a utilização delas na busca pela sua autonomia e no despertar da curiosidade (DEMO, 2011). 
Gadotti ressalta que "na era do conhecimento deverá surgir também um novo aluno, sujeito de sua própria formação, autônomo, motivado para aprender, disciplinado, organizado, mas cidadão do mundo, solidário, e, sobretudo, curioso" (GADOTTI, 2009, p. 46).

"Daí a importância de recuperar uma pedagogia da pergunta e não só da resposta, favorecedora de uma aprendizagem baseada mais no diálogo do que no monólogo. Falamos de imaginação, de capacidades, de estímulos, (...)”(IBERNÓN, 2008, p.89).

Os avanços tecnológicos e a capacidade de acesso às informações surgem como um desafio ao ensino tradicional em que o docente atua como mero transmissor de conhecimentos (DEMO, 2011).

Com isso, a educação do século XXI vem buscando fortalecer a formação de agentes de transformação que, por meio de indagações, contribuições e interações oferecem um mais qualificado processo de ensino-aprendizagem (MANHÃES, 2009).

As novas configurações do mundo do trabalho e os diferentes contextos sociais em que estamos inseridos vêm exigindo da sociedade capacidade de tomar decisões, de possuir habilidades comunicativas, de desenvolver trabalhos em grupo, polivalência, flexibilidade e capacidade de pensar, questionar e aprender a aprender (GOMEZ; SACRISTÁN, 2007; (WALL, PRADO; CARRARO, 2008).

A Educação no Século XXI requer processos pedagógicos abertos, dinâmicos e criativos, devendo os sujeitos estarem em permanente atitude de aprendizagem, de investigação e da busca pelo saber construído (PRADO, 2008).

Tornar o processo educativo capaz de despertar a curiosidade e a capacidade crítica dos educandos é uma importante estratégia para formar uma sociedade aprendente, pensante e atuante.

Para isso, na sala de aula se deve buscar um processo de criação e transformação de significados, onde o docente orienta e conduz as trocas de conhecimentos entre estudantes, de modo que os saberes sejam compartilhados, questionados e enriquecidos (GOMEZ, SACRISTÁN, 2007).

\subsection{A DODICÊNCIA E O PROCESSO DE ENSINO APRENDIZAGEM}

No processo de ensino aprendizagem, o docente deve assumir uma postura investigativa de sua própria prática, conforme aponta Perrenoud (2002, p.11): “ele não conhece de antemão 
a solução dos problemas que surgirão em sua prática; deve construi-la constantemente ao vivo (...). Isso não pode acontecer sem saberes abrangentes, saberes acadêmicos, saberes especializados e saberes oriundos de experiência”.

Assim, quando integrados os saberes, torna-o docente capaz de atuar como mediador, facilitador, ativador da capacidade de autonomia do estudante e de sua reflexão, por meio da problematização da realidade e do estímulo aos trabalhos em equipe (MORAN, 2014; MENDES, 2013).

Ao tratar da realidade inserida e contextualizada no ensino, tem-se a práxis como capaz de favorece a aprendizagem, uma vez que associa a teoria à prática, de modo que o estudante se torna capaz de apreender novos saberes e interagir em diferentes contextos, devendo os debates não se restringirem às escolas, mas envolver os problemas reais (PRADO, 2008).

Desse modo, compreende-se que a contextualização do conhecimento às realidades vivenciadas pelos envolvidos no processo de ensino aprendizagem auxilia na compreensão de um saber aplicado que pode ser facilmente associado às situações do dia a dia do discente, de modo que o docente possa guiar o processo educativo tornando-o parte integrante (FREIRE, 2010; MORIN, 2011).

Segundo Freire (2011), para o processo de ensino aprendizagem, a dodiscência assegura a proposição de um ambiente em que estudantes reconheçam suas próprias ideias, a interação delas com as de outras pessoas, igualmente válidas, e que possam ser discutidas considerando as teorias abordadas em sala de aula.

No processo de ensino-aprendizagem, caberá ao docente, além de conhecer o conteúdo programático, conduzir o discente a aprender a aprender, a partir de um processo de reflexão de suas aulas, dos métodos e princípios de aprendizagem e dos caminhos necessários a um processo educativo em constante adaptação. Para isso, é necessário que o próprio docente se abra a novas formas de pensar e atuar em sala de aula a partir das experiências trocadas (TARDIF, 2010; REHEM, 2009).

Em complemento, Pacheco e Morigi (2012) orientam a importância de o docente refletir sobre seu papel enquanto formador de cidadãos na construção de um processo de reflexão e ação. Como ressalta Freire (2011), cabe ao educador exercer papel de mediador e motivador, não apenas ensinando conteúdos, mas a pensar de forma correta, muitas vezes, atuando como um professor gestor. 
Ao tratar do cerne do papel do professor gestor, os autores Ésther e Melo (2008, p.17), reconhecem que o professor-gestor é "uma espécie particular de gerente, [....] eles possuem funções e papeis peculiares ao mundo acadêmico, na medida em que são, antes de tudo, em geral, professores de carreira" [....].

Além disso, cabe ao docente o desenvolvimento de um papel social representado com comportamentos que resultem em um processo contínuo de construção social visando ao atendimento de expectativas e necessidades das pessoas que exerce influência (BARBOSA; MENDONÇA; PAIVA, 2018; LIBÂNEO, 2002).

Desse modo, considerando o reconhecimento do docente gestor, no âmbito acadêmico, e a necessidade de seu papel social para a busca da construção de um caminho interativo entre docentes e sujeitos influenciados por eles, pode-se, também, apontar a abordagem de uma perspectiva cujos basilares são a liderança como uma forma de conduzir, envolver e estimular o educando a ser parte dessa construção social direcionado à prática educativa em que ambos ensinam e aprendem (CARAVANTES; PANNO; KLOECKNER, 2005).

\section{BREVES CONSIDERAÇÕES SOBRE A TEORIA DA LIDERANÇA}

Robbins, Judge e Sobral (2010) define liderança como a capacidade que as pessoas têm de influenciarem outras pessoas para alcançar objetivos e metas, podendo ser essa influência formal, por meio do exercício do cargo dentro da organização, ou informal, a partir do surgimento de liderados, que têm aquela pessoa como referência para suas ações. Afinal, nem todos os líderes são gestores e nem todos os gestores são líderes.

A liderança é um mecanismo cujo agente é capaz de identificar as diferentes personalidades, culturas, costumes, potenciais, concepções, vivências que mudam de pessoa para pessoa e reconhecer o valor de cada uma delas. Com isso, espera-se do líder a capacidade de entender e lidar com as diferentes dificuldades existentes, as necessidades motivacionais, o estímulo ao trabalho em equipe e à constante busca pelo despertar da criatividade e da melhoria contínua (ESCORSIM; WALGER, 2017; STOCKER, 2018).

Para Dubrin (2006, p. 264), a liderança é definida como a "habilidade de inspirar confiança e apoio entre as pessoas de cuja competência e compromisso depende do desempenho." 
Outrossim, a liderança tem fundamental papel para influenciar e conduzir ações, comportamentos, atitudes e seus respectivos impactos à organização e as partes interessadas. Nesse sentido, o líder consegue influenciar a mentalidade das pessoas, orientando-a aos caminhos mais seguros e eficazes (LIU et al., 2018).

Segundo Robbins, Judge, Sobral (2010), a liderança é como um processo que busca o gerenciamento de mudanças, é estruturada por relacionamentos baseados em confiança mútua, em respeito às ideias diferentes, com a busca de metas definidas para o devido alcance e o cuidado com os sentimentos dos liderados envolvidos. "Os líderes estabelecem direções por meio do desenvolvimento de uma visão do futuro; depois, engajam as pessoas, comunicandolhes essa visão e inspirando-as a superar os obstáculos" (ROBBINS; JUDGE; SOBRAL, 2010, p.359).

O líder atua como uma ponte entre os interesses organizacionais e a orientação para o caminho necessário ao alcance dos objetivos. Tem-se no líder aquele capaz de se utilizar de suas habilidades e competências para mobilizar o melhor das pessoas em prol de objetivos (MANDELLI; LORIGGIO, 2018).

O líder necessita escutar a opinião, os anseios e as necessidades de seus subordinados, prestando apoio, quando necessário, atuando para o bem coletivo e gerando novas estratégias para assegurar melhorias de forma continuada (BARBOSA; MENDONÇA, 2014; PAUNOVA, 2017). Apesar de caber ao líder a responsabilidade no processo decisório, ele não é o detentor do saber, devendo, inclusive, estimular a construção coletiva de ideias. Afinal, a participação daqueles que são subordinados na instituição traz para ele o sentimento de pertencimento e de responsabilidade de fazer acontecer (PAUNOVA, 2017).

Outrossim, segundo Robbins, Judge e Sobral (2010, p.361), "ao contrário da amabilidade e da estabilidade emocional, a conscienciosidade e a abertura a novas experiências também se mostraram fortemente associadas à liderança, mas essa relação não era tão forte quanto com a extroversão". Nesse sentido, concorda-se com Robbins que o líder necessita criar espaços de aprendizagem e de novas experiências para desenvolver no outro uma determinada consciência para tomada de decisões e comportamentos assertivos.

\section{PROCEDIMENTOS METODOLÓGICOS}

Revista Expectativa, Toledo/PR, v.20, n. 3, p. 71-87, jul./set., 2021. 
O percurso metodológico teve como embasamento as discussões teóricas dos conceitos de Liderança, Dodiscência e suas respectivas aproximações conceituais. A investigação foi desenvolvida baseando-se na pesquisa bibliográfica, a partir de uma pesquisa mais aprofundada sobre os temas por meio de artigos científicos, dissertação e livros que têm as referidas temáticas, a partir dos dados secundários oriundos de trabalhos publicados e realizados por outros autores (TOZONI-REIS, 2009).

Quanto aos objetivos o estudo, caracterizou-se como descritivo tendo seus objetivos bem definidos e a pesquisa adequadamente conduzida para descrever os dados identificados (DUARTE; BARROS, 2010).

Segundo as bases lógicas da investigação, trata-se de um estudo dedutivo que se desenvolve pela particularização, cuja análise da construção teórica forneceu suporte para que a teorização possa promover a discussão e percepção dos fenômenos de interesse do autor do presente estudo (MARCONI; LAKATOS, 2017).

O arcabouço teórico que subsidiou a análise acerca da aproximação teórica entre dodiscência e liderança foi desenvolvido por meio da leitura de textos extraídos sobre a temática nos periódicos indexados nas bases de dados SciELO, Scopus, Spell, Google Acadêmico (SEVERINO, 2016). No processo de indexação na base de dados bibliográficos, a busca foi realizada a partir de vocabulário controlado (palavras-chave), considerando às temáticas do estudo.

\section{A LIDERANÇA COMO UMA ESTRATÉgIA DE FORTALECIMENTO DA DODISCÊNCIA}

Considerando que o exercício da dodiscência requer o envolvimento de docentes e discentes, devidamente interessados em construir conhecimentos, por meio da interação e da partilha de saberes, faz-se necessário desenvolver uma relação em que a liderança seja a estratégia que guie o engajamento discente-docente e, a partir da inspiração, o discente se sinta motivado à busca pela produção de novos conhecimentos e pela capacidade de atuar com os demais estudantes para um objetivo coletivo: o saber construído conjuntamente (MCGREGOR et a.l, 2016).

Revista Expectativa, Toledo/PR, v.20, n. 3, p. 71-87, jul./set., 2021. 
Nesse sentido, observa-se que a relação entre o processo de motivação, envolvimento, confiança e orientação para determinado fim são fatores de convergência conceitual entre a liderança e a dodiscência.

O docente deve ser líder para, a partir de suas abordagens em sala de aula, estimular nos estudantes o desenvolvimento de uma consciência para os problemas sociais que circundam a existência de cada um deles para que eles sejam transformados e, a partir disso, sejam capazes de transformar (MORAN, 2014; MENDES, 2013).

Nesse sentido, percebe-se que a dodiscência está imbricada ao desenvolvimento de um docente líder, pois apenas com a capacidade de envolver e de estabelecer a relação de confiança com os estudantes, poderão ser despertados no discente a reflexão e o desejo de ser agente de transformação.

Enquanto gestores-líder estabelecem esse processo para transformar as pessoas para que elas auxiliem a organização ao alcance da performance organizacional, docentes-líder resgatam o melhor do discente para que, por meio de sua autonomia, seja capaz de construir saberes para transformar cenários sociais, individuais e organizacionais (LICHTENTHALE; FISCHBACH, 2018).

Assim, pode-se inferir que cabe, conjuntamente, àqueles envolvidos com a liderança e a dodiscência a responsabilidade de inspirar pessoas com uma determinada finalidade e, para isso, necessitam desenvolver estratégias para inspirar, envolver e conhecer novos caminhos. Nesse sentido, o docente líder tem a sua devida importância, pois seu exemplo e capacidade de agregar novas pessoas para alcançar os objetivos pretendidos podem levar ao sucesso ou a fracasso.

Outra importante aproximação conceitual é a relevância do feedback para compor a relação na liderança e na dodiscência, pois a captação de informações para melhoria contínua e a retroalimentação, por meio da ação-reflexão-ação, reconhecendo no estudante capacidade de retroalimentar novos conhecimentos visando ao enriquecimento dos conteúdos abordados.

Acrescenta-se a esta concepção, a necessidade de humildade, desprendimento, capacidade para transformar os conhecimentos do educando em retroalimentação para o contínuo diálogo em sala de aula.

Essa retroalimentação no âmbito da liderança de uma organização pode ser observada para melhoria dos resultados e dos processos organizacionais, quando observada para o âmbito educacional em que o docente nesse de retroalimentação por meio de feedbacks e participação 
de estudantes, tem-se a observância em que se trata de um aperfeiçoamento do conteúdo discutido pelo docente sob a perspectiva da vivência do aluno, fortalecendo e contextualizando aquele saber à práxis do educando (STOKER, 2018; FREIRE, 2010).

Por outro lado, observa-se que a liderança se relaciona com a dodiscência, pois se acredita que a liderança pode ser desenvolvida na formalidade ou na informalidade, enquanto a dodiscência requer uma formalidade que designa o docente para estar sob a responsabilidade de exercer sus prática laboral.

Tem-se, também, a divergência de que a liderança não precise ser desenvolvida exclusivamente em sala de aula, mas a dodiscência é exclusiva de um processo de ensino aprendizagem dentro do ambiente escolar ou de situações correlatas no âmbito acadêmico.

A análise das temáticas liderança e dodiscência, quando integrados ao processo de ensino aprendizagem, apresentaram aproximações conceituais no que concerne à necessidade de a relação entre docente e estudante ser balizada por meio de uma confiança mútua para a realização de um desenvolvimento educativo eficaz. A confiança permite que o discente acredite nas diretrizes estabelecidas pelo docente, mas que também acredite na sua potencialidade em complementar, discordar, reanalisar e se tornar um constante curioso.

Além disso, observa-se a capacidade de interagir socialmente como uma resposta à construção de uma relação amadurecida pelas experiências existentes, pelo ato de envolvimento do docente em reconhecer os diferentes estudantes e seus potenciais que compõem aquela esfera social. Reconhecer que cada um pode dar o seu melhor, dentro dos diferentes limites, das diferentes potencialidades também é uma olhar necessário à relação de dodiscência, mas também à condução da liderança (SILVA; SIQUEIRA; BARROS, 2019).

Ser um exemplo, um guia, também são características necessárias à dodiscência e à liderança, sendo ambos parte de um processo que se relacionam docente-discente/liderado/líder na perspectiva de ter no outro a inspiração para dar o seu melhor, para escutar, direcionar seus caminhos, conduzir as relações.

Dessa forma, compreende-se que a busca pela liderança pode ser constantemente buscada e aperfeiçoada pelo docente e que esta pode fortalecer a dodiscência no processo de ensino e aprendizagem. Para isso, é necessário demonstrar conhecimento das necessidades dos educandos, ter conhecimento e capacidade para influenciar na solução de problemas e desenvolver confiança para trazer novas ideias e problemas vivenciados para busca conjunta de soluções (MORAN, 2014; MENDES, 2013). 
O líder dodiscente deve buscar, junto ao educando, compreender seu papel no processo educativo, desenvolver nele a busca pela autonomia e a criticidade e atuar diante dos problemas que os circundam. Assim, são exigidos que os preceitos da formação de docentes líderes sejam capazes de influenciar e inspirar discentes, usando-se, inclusive, da humildade para reconhecer a centralidade do saber do discente como parte fundamental ao ensino na contemporaneidade.

\section{CONSIDERAÇÕES FINAIS}

Finalmente, reconhece-se que a liderança e a dodiscência possuem aproximações conceituais e que, quando a liderança é integrada ao processo de ensino-aprendizagem, tem-se a potencialização e melhores condições do exercício da dodiscência, uma vez que as relações docente-discente, discente-discente e discente-docente necessitam de um processo contínuo de estímulo, confiança e direcionamento.

Observa-se que a liderança é capaz de despertar nos sujeitos a sua participação e envolvimento na busca por um processo educativo em que ambos ensinam e ambos aprendem. Nesse sentido, a liderança fortalece a dodiscência, pois promove percepções, atitudes e comportamentos que asseguram uma maior responsabilização e envolvimento do estudante na sua atuação em sala de aula.

Com isso, a capacidade de persuasão e inspiração de cada líder docente revela maiores condições de uma dodiscência efetiva, cujo estudante ocupa a centralidade, e, por isso, denomina-se uma relevante estratégia de fortalecimento da dodiscência.

Para estudos futuros, sugere-se a discussão dessa dodiscência e da liderança no ensino remoto e como essa dodiscência pode contribuir como a consciência sustentável dos sujeitos envolvidos.

\section{REFERÊNCIAS}

ASSMANN, H. Reencantar a educação. Rumo à sociedade aprendente. 5. ed. Petrópolis: Vozes, 2001.

BARBOSA, M.; MENDONÇA, R. O Professor-Gestor em Universidades Federais: alguns apontamentos e reflexões. Teoria e Prática em Administração, v. 4, n. 2, p. 131-154, 2014.

BARBOSA, M. A. C; PAIVA; K. C. M., MENDONÇA, J. R. C. Papel social e competências gerenciais do Professor do Ensino Superior: aproximações entre os

Revista Expectativa, Toledo/PR, v.20, n. 3, p. 71-87, jul./set., 2021. 
construtos e perspectivas de pesquisa: O\&S - Salvador, v. 25, n. 84, p. 100-121, jan./mar. 2018

BERGER, P. L.; LUCKMANN, T. A Construção Social da Realidade. Petrópolis: Vozes, 2005.

CARAVAnteS, G. R., PANNO, C. C., KLOECKNER, M. C. Administração: teorias e processo. São Paulo: Pearson, 2005.

COUTINHO, C.; LISBOA, E. Sociedade da Informação, do Conhecimento e da Aprendizagem: Desafios para Educação no Século XX. Revista de Educação, v. 18, n. 1, p. 5-22, 2011.

COSTA, T. P.; CHIZZONI, C. C.; VAZ, C. F. M. Secretários remotos ou in company: como se apresenta o mercado remoto para os profissionais de secretariado? Secretariado Executivo em Revist@, v. 15, n. 1, p. 62-76, 2019.

DEMO, P. Olhar do educador e novas tecnologias. Boletim Técnico do Senac, v. 37, n. 2, p. 15-26, 19 ago. 2011.

DIESEL, A.; SANTOS BALDEZ, A. L.; NEUMANN MARTINS, S. Os princípios das metodologias ativas de ensino: uma abordagem teórica. Revista Thema, v. 14, n. 1, p. 268$288,2017$.

DUARTE, J. B. A., BARROS, A. Métodos e Técnicas de Pesquisa em Comunicação. 2. ed. São Paulo: Atlas, 2010, 380p.

DUBRIN, A. J. Fundamentos do Comportamento Organizacional. São Paulo: Pioneira, 2006.

ESCORSIN, A. P.; WALGER, C. Liderança e desenvolvimento de equipes: Livro Eletrônico. Curitiba: Inter Saberes 2017.

ÉSTHER, A. B.; MELO, M. C. O. L. A construção da identidade gerencial dos gestores da alta administração de universidades federais em Minas Gerais. Cadernos EBAPE. BR, v. 6, n. 1, p. 1-17, 2008.

FREIRE, P. Pedagogia do Oprimido. São Paulo: Editora Paz e Terra LTDA, 2010, 213p.

FREIRE, P. Pedagogia da Autonomia. São Paulo: Editora Paz e Terra LTDA, 2011, 143p.

GADOTTI, M. Pedagogia da Terra. Petrópolis: Brasil Editora. 2009. 217p.

GÓMEZ, P. A. I.; SACRISTÁN, M, G. J. Compreender e transformar o ensino. 4. ed., Porto Alegre: Artmed, 2007, 391p.

HALAL, C.Y. Ecopedagogia: uma nova educação. Revista de Educação. v. XII, n. 14, 2009. 
IMBERNÓN, F. Amplitude e profundidade do olhar: a educação ontem, hoje e amanhã. In: IMBERNÓN. F. (Org). A Educação no século XXI: os desafios do futuro imediato. São Paulo: ARTMED, 2008, 205p.

IMBERNÓN, F. Educação para o século XXI: os desafios do futuro imediato. In: IMBERNÓN. F. (Org). A Educação no século XXI: os desafios do futuro imediato. São Paulo: ARTMED, 2008, 205p.

LAKATOS, E. M.; MARCONI, M. A. Fundamentos de metodologia científica. 7. ed. São Paulo: Atlas, 2017.

LIBÂNEO, J. C. Reflexividade e formação de professores: outra oscilação do pensamento pedagógico brasileiro? In: PIMENTA, S. G.; GHEDIN, E. (Orgs.). Professor reflexivo no Brasil - gênese e crítica de um conceito. São Paulo: Cortez, 2002.

LICHTENTHALER, P. W; FISCHBACH, A. Leadership, job crafting, and employee health and performance. Leadership \& Organization Development Journal, v. 39, n.5, p. 620$632,2018$.

LIU, C; READY, D; ROMAN, A; VAN WART, M; WANG, X; MCCARTHY, A; KIM, S. E-leadership: an empirical study of organizational leaders' virtual communication adoption. Leadership \& Organization Development Journal, v. 39, n. 7, p-826- 843, 2018.

MANDELLI, P.; LORIGGIO, A. Exercendo liderança: O papel central do líder, sua motivação, proatividade e equilíbrio emocional. Editora Vozes Limitada, 2018.

MANHÃES, H. A prática pedagógica ação dialógica na construção de identidades. Rio de Janeiro, 2009, 88p.

MARCONI, M. A.; LAKATOS, E. M. Fundamentos de metodologia científica. 8. ed. São Paulo, SP: Atlas; GEN, 2017. 346 p.

MCGREGOR, A; MAGEE, C. A.; CAPUTI, P.; IVERSON, D. L. A job demands resources approach to presenteeism. Career Development International, v. 21, n. 4, p. 402-418, 2016.

MELO, A.; URBANETZ, S. T. Fundamentos de Didática. Curitiba: IBPEX, 2008, 188p.

MENDONÇA, J. R. C. et al. Competências profissionais de professores do ensino superior no Brasil: proposta de um modelo integrado. In: FÓRUM DA GESTÃO DO ENSINO

SUPERIOR NOS PAÍSES E REGIÕES DE LÍNGUA PORTUGUESA, 2, 2012, Macau, China. Anais [...]. Macau, China: Instituto Politécnico de Macau, 2012. Disponível em: Acesso em: 10 dez. 2019.

MENDES, F. R. A nova sala de aula. Porto Alegre: Editora Autonomia, 2013.

MORAN, J. Novos modelos de sala de aula. Revista Educatrix, v. 7, p. 33-37, 2014. 
PACHECO, E. M. MORIGI, V.; Ensino Técnico, Formação Profissional e Cidadania. Porto Alegre: Teckne, 2012, 120 p.

PAUNOVA, M. Who gets to lead the multinational team? An updated status characteristics perspective. Human Relations, v. 70, n. 7, p. 883-907, 2017.

PERRENOUD, P. A prática reflexiva no ofício de professor: profissionalização e razão pedagógica. Porto Alegre: Artmed, 2002.

PRADO, F. G. C. Ecopedagogia e cidadania planetária. 4. ed. São Paulo: Cortez: Instituto Paulo Freire, 2008.

ROBBINS, S. P.; JUDGE, T.; SOBRAL, F. Comportamento organizacional: teoria e prática no contexto brasileiro. 14. ed. São Paulo: Pearson, 2010.

SEVERINO, A. J. Metodologia do trabalho científico. 24. ed. São Paulo: Cortez, 2016.

SILVA, W. F.; SIQUEIRA, N. C.; BARROS, W. B. A Indissociabilidade do Ensino, Pesquisa e Extensão na perspectiva de uma formação secretarial sustentável. Revista Expectativa, v.18 n. 2, jul./dez., 2019.

SILVA, W. F. A dodiscência na Educação Profissional e Tecnológica para o Desenvolvimento Local Sustentável no Instituto Federal de Educação, Ciência e Tecnologia de Pernambuco, Campus Ipojuca. Dissertação (Mestrado em Gestão do Desenvolvimento Local Sustentável) - Universidade Federal de Pernambuco, Recife: UPE, 2013.

STOCKER, F. E-Leadership: Reflexões e Desafios da Liderança Empresarial Contemporânea. Revista Expectativa, v.17, n.2, jul./dez., 2018

TOZONI-REIS, M. F. C. Metodologia da Pesquisa. 2. ed. Curitiba: IESDE Brasil S.A., 2009.

VIGOTSKY, L. A Formação social da mente. São Paulo: Martins Fontes, 1991.

WALL, M. L.; PRADO; M. L.; CARRARO, T. E. A experiência de realizar um estágio na docência aplicando metodologias ativas. Acta Paulista de Enfermagem, São Paulo, v. 21, n. 3, p. 515-519, 2008. 